\title{
SITIO, OFENSIVA Y CAPITULACIÓN DE LA CIUDAD DE PAMPLONA EN 1823. LA CONSOLIDACIÓN DE LA RUPTURA IDEOLÓGICA Y SOCIAL DE NAVARRA EN EL OCASO DEL ANTIGUO RÉGIMEN ESPAÑOL
}

SIEGE, OFFENSIVE AND CAPITULATION OF THE CITY OF PAMPLONA IN 1823. THE CONSOLIDATION OF THE IDEOLOGICAL AND SOCIAL RUPTURE OF NAVARRA IN THE CASE OF THE ANCIENT SPANISH REGIMENT

\author{
Francisco José Alfaro Pérez ${ }^{1}$ \\ Universidad de Zaragoza
}

Entregado el 17-1-2013 y aceptado el 8-3-2013.

Resumen: De abril de 1823 a septiembre de aquel mismo año la ciudad de Pamplona padeció un largo asedio que concluyó con la capitulación de la misma frente a un ejercito sitiador integrado por fuerzas realistas españolas y el quinto cuerpo del ejército francés de los Pirineos, comandado por el Conde de Molitor, fracción de los más conocidos como Cien mil hijos de San Luís. En el estudio aquí presentado, la aparición de nuevas fuentes documentales ha permitido realizar una relectura de aquellos acontecimientos, puntualizando y ampliando lo ya dicho en otros trabajos. Su objetivo, entender un poco mejor aquella intrahistoria o algunos porqués de un tiempo convulso que marcaría en buena media el devenir histórico de la sociedad española decimonónica.

Palabras clave: Absolutismo, Restauración, Trienio Liberal, Pamplona, Cien Mil Hijos de San Luis.

${ }^{1}$ El presente estudio participa en el proyecto de investigación HAR 2012-34576 del Ministerio de Economía y Competitividad dirigido por la profesora Encarna Jarque Martínez y en el proyecto de innovación PESUZ_12_1_392, 2012-2013, que dirijo. 


\begin{abstract}
From April 1823 through September of the same year, the city of Pamplona suffered a long siege which ended with its capitulation after being besieged by an army composed of Spanish royalist forces and the Fifth Corps Army of the Pyrenees. The army was commanded by the Count of Molitor, a fraction of the most known one-hundred thousand children of St. Luis. Presented here in the study, the appearance of new source documents allowed for the reinterpretation of important events and expanded on what has been said in other works. Your objective is to better understand a little more of the inside story and answer some questions of this troubled time, a large part of which would make a marka in the historical Spanish society in the nineteenth century, more specifically in Pamplona.
\end{abstract}

Key words: Absolutism, Restoration, Liberal Triennium, Pamplona, Hundred Thousand Sons of St. Louis. 
La Navarra del Trienio Constitucional y, más concretamente, su violento final es un tema bastante trabajado aunque, como trataré de mostrar, algunos aspectos analíticos tienen aún cierto recorrido. A las publicaciones apasionadas salidas de la pluma de las personas que vivieron in situ los acontecimientos como es el caso del cura de Uztárroz, ${ }^{2}$ del Vizconde de Martignac, ${ }^{3}$ del general A. Hugo, ${ }^{4}$ etc.,${ }^{5}$ u otras relativamente próximas, bien en el tiempo, bien por seguir ortodoxamente a quienes lo estuvieron - como P. G. de Bussy ${ }^{6}$ o G. de Grandmaison,$-{ }^{7}$ han continuado otras muchas más recientes (y más objetivas) en las que no me detendré más allá de citar su existencia. ${ }^{8}$

2 Andrés Martín, Historia de la guerra de la División Real de Navarra contra el intruso sistema llamado constitucional y su gobierno revolucionario, Imprenta de Javier Gadea, Pamplona, 1825.

${ }_{3}$ Vicomte de Martignac, Essai historique de la Revolution d'Espagne et sur l'intervention de 1823, A. Pinard, Imprimeur-Libraire, t. I, Paris, 1832.

${ }^{4}$ Abel Hugo, Historie de la campagne d'Espagne en 1823, Imprimerie de Jules Didot Aine, t. I y II, Paris, 1824-1825.

5 Pudiéndose destacar, por ejemplo, las publicaciones de Horace Raisson, Histoire de la guerre d'Espagne en 1823, Chez J. P. Roret (Éditeur), Paris, 1827; o, de un tono más político, el de Jean François Caze, La vérité sur l'Espagne, Ponthieu et Lenormant, Paris, 1825; entre otros.

${ }^{6}$ P. G. de Bussy, «Campagne et souvenirs d'Espagne (1823)», Revue Hispanique: recueil consacré à l'étude des langues, des littératures et de l'histoire des pays castillans, catalans et portugais, t. XXXII, 1914, pp. 458-569.

7 Geoffroy de Grandmaison, L'expedition française d'Espagne, Paris, 1928.

8 Aunque tampoco puedo pasar por alto la mención, por orden alfabético, de algunas de las más destacadas como pueden ser, por ejemplo: José Luís Canellas, Los realistas en el Trienio Constitucional, Pamplona, 1958; Ángel García-Sanz Marcotegui, «Elites económicas y políticas en la Restauración: la diversidad de las derechas navarras», Historia Contemporánea, núm. 23, 2001, pp. 577-628; José Fermín Garralda Arizcun, «Antecedentes de la Guerra Carlista. Estudio socio-político de Pamplona en el Trienio Liberal (1820-1823)», Revista Príncipe de Viana, núm. 181, 1987, pp. 487-526; M. ${ }^{a}$ C. Laboria Erroz, «Navarra frente al constitucionalismo gaditano» (I) y (II) Revista Príncipe de Viana, núms. 112-113 y 114-115, 1968 y 1969, pp. 273-326 y 53-108, respectivamente; André Lebourleux, La croisade des cent mille fils de Saint Louis: l'expédition française en Espagne de 1823, Dualpha, 2006; Jesús Luís del Campo, «Pamplona tres lustros de su historia (1808-1823) (II)», Revista Príncipe de Viana, núm. 163, 1981, pp. 495-559; M. ${ }^{a}$ Cruz Mina Apat, Fueros y Revolución liberal en Navarra, Alianza, Madrid, 1981; Francisco Miranda Rubio, «La quiebra del Antiguo Régimen en Navarra y la Revolución Liberal (1808-1836)», Actas del V Congreso de Historia de Navarra, vol. 3, Pamplona, 2002, pp. 143-186; Ángel Ramón del Río Aldaz, Orígenes de la guerra carlista en Navarra, Pamplona, 1987; o Jean Vidalenc, Aspects de la guerre d'Espagne de 1823, Cahiers de Montpellier, 1983; entre otros muchos. 
Uno de los motivos que me animó a realizar el presente estudio fue el hallazgo de una serie de fuentes inéditas donde, de manera minuciosa y precisa, se recogían algunos aspectos desconocidos del sitio y de la batalla librada en la Pamplona del año 1823. La aparición de un diario anónimo escrito (desde dentro) por uno de los liberales sitiados y la relectura de unas fuentes periodística pro-realistas (desde fuera), muy poco trabajadas, han permitido no sólo cotejar sus datos con la versión oficialista y la historiográfica, sino también la obtención de una amplia gama de matices y de detalles informativos que vienen a enriquecer, completar e incluso reinterpretar lo ya sabido. Así pues, no es éste un simple ejercicio de erudición. Consciente de que la «gran» historia hace mucho tiempo que ya está escrita, el objetivo aquí propuesto no podía ser otro que el de tratar de conocer un poco mejor la intrahistoria, las relaciones, los porqués de comportamientos ilógicos o de difícil explicación sin otros argumentos. Tarea ardua, compleja y siempre inconclusa dado que para ello se precisan «pequeños» detalles (personas, nombres, intereses, enlaces, redes, etc.) y que, además, éstos provengan de fuentes desnudas - amparadas en el anonimato o gestadas en la creencia de su privacidad como pueden ser diarios, epístolas, borradores, etc. - escasas y difíciles de encontrar por su propia naturaleza, pero que de vez en cuando, como en esta ocasión, se tiene la fortuna de disponer.

\section{Una sociedad dividida: Navarra (1820-23)}

Los cambios gestados en los escasos años transcurridos desde la proclamación de la Constitución de 1812 y el ansiado retorno de Fernando VII (III de Navarra), hasta la sublevación del coronel Riego, entre enero y marzo de 1820, han marcado en buena medida el devenir histórico de la España contemporánea. En ellos, el Deseado no sólo se convirtió en Felón, sino que su reconocida impericia empujó a la política interior española a una deriva trágica. ${ }^{9} \mathrm{El}$ pueblo lo coronó y él, en pago, quiso gobernar como antaño, sin contar con sus súbditos. Abolió la Constitución, consumó la pérdida de casi todas las posesiones españolas ultramarinas y pasó a considerar traidores a muchos de aquellos héroes nacionales de la

9 Véase, entre otros, Josep Fontana, La quiebra de la monarquía absoluta, 1814-1820, Ariel, Barcelona, 1971. 
guerra de la Independencia por el mero hecho de no comulgar ideológicamente. Bien es cierto, también, que la coyuntura que le tocó gobernar no era nada sencilla.

Para contextualizar los hechos, recordemos como la tentativa de Riego por recuperar el sistema constitucional triunfaría en 1820 a pesar de su tibieza inicial. Un éxito temporal (de tres años) e incompleto salpicado de insistentes conatos conspirativos e insurrecciones, en suma una guerra sórdida y larvada. En este proceso, la fractura abierta en la sociedad navarra - acentuada en tiempos de la ocupación extranjera una década antes - volvió a quedar al descubierto. ${ }^{10}$ De este modo, por ejemplo, ciertas localidades como Falces, Mañeru, Marcilla, Olite, Peralta, Sumbilla o Tudela - algunas de ellas pertenecientes a señoríos jurisdiccionales - celebraron la caída de los símbolos «feudales»; otras en cambio, como Burgui, Corella, Fustiñana, Mendigorría o Vera de Bidasoa, a los pocos meses de implantarse el nuevo sistema, comenzaron a padecer actos vandálicos contra los emblemas y monumentos erigidos en honor a la Constitución; mientras que el resto del reino se mecía al vaivén de la postura adoptada por una elite local asida a sus gobiernos municipales generación tras generación. ${ }^{11}$

En abril del mismo año 1820, el ayuntamiento pamplonés y unos cuantos vecinos mostraron abiertamente su malestar por el hecho de que los liberales de la localidad se dotaran y tutelaran con una milicia de voluntarios fusileros, aduciendo que ese proceder no era compatible con el derecho consuetudinario que la capital navarra tenía para levantar tercios. El 22 de julio hicieron pública su protesta con un manifiesto, pero

10 Véase, por ejemplo, un caso de la Ribera de Navarra en Francisco José Alfaro Pérez, «El clan del Corrús o la crisis del Antiguo Régimen en los Montes de Cierzo. Contribución al estudio de la formación de la ideología política en el ámbito rural navarro del siglo XIX», Actas del VI Congreso de Historia de Navarra, vol. 2, Pamplona, 2006, pp. 3-16.

11 Véanse F. Idoate, «Afuera los símbolos de vasallaje», Rincones de la Historia de Navarra, Gobierno de Navarra, vol. 2, (1. ${ }^{\mathrm{a}}$ ed. 1966), pp. 106-113, y «iAbajo la Constitución», Id., pp. 114-119. Tanto los postulados liberales como los contrarrevolucionarios, obviamente, no se circunscribieron solo a Navarra sino a toda España. Véase, por ejemplo, J. Veríssimo Serrao y A. Bullón de Mendoza, La contrarrevolución legitimistas (1686-1876), Universidad Complutense, Madrid, 1995. La división que tradicionalmente se ha venido de Navarra, entre zonas de predominio liberal (más hacia el sur) y realistas - luego carlistas - (más hacia el norte), aunque siempre con multitud de excepciones, seguramente, deberían ser revisadas ya que se han practicado en función del color político de los gobernantes municipales, lo que, dado que no era un sistema democrático, no significa que el pueblo compartiera la misma tendencia. 
el asunto no pasó de ahí. ${ }^{12}$ Por su parte, los pamploneses fieles al liberal Espoz y Mina prosiguieron operando a su conveniencia llegando a impedir, por la fuerza, la entrada del jefe político de la provincia, el pro-realista corellano Miguel Escudero. ${ }^{13}$ En los aderezos de estas tensiones fue donde, el 29 de enero de 1821, estallaría el primer incidente serio entre los militares acantonados - apoyados por paisano liberales - y un grupo de vecinos realistas. Los esfuerzos del liberal cirbonero Pedro Clemente de Ligués, ${ }^{14}$ nuevo jefe político, para reconducir la situación no surtieron el efecto deseado y el ambiente siguió enrareciéndose cada vez más en los meses venideros. Comenzaron a elaborarse listas de adeptos a una $\mathrm{u}$ otra causa, ${ }^{15}$ al tiempo que aumentaba un nervioso ir y venir de gentes. ${ }^{16}$ El 12 de mayo del mismo 1821 se anunció desde Madrid el envío a Pamplona de 8 compañías de granaderos provinciales de Castilla la Vieja en lugar del esperado regimiento Imperial Alejandro, lo que hizo correr el rumor por toda la ciudad de que venían «a sujetar Navarra». El verano y el otoño no lograron calmar los ánimos de algunos pamploneses, sobre todo los de las calles San Gregorio, San Lorenzo y Pellejería donde al parecer se mostraban especialmente inquietos.

${ }^{12}$ A(rchivo) M(unicipal de) P(amplona), Consultas, Libro n. ${ }^{\circ}$ 76, ff. 45-51.

13 Sobre la influencia de esta familia en las instituciones navarras desde el siglo XVI hasta el XIX (y XX), así como en su localidad de origen, véase la obra de Francisco José Alfaro Pérez y Begoña Domínguez Cavero, Sociedad, Nobleza y Emblemática en una ciudad de la Ribera de Navarra. Corella (Siglos XVI-XVIII), Institución Fernando el Católico (CSIC) y Gobierno de Navarra, Zaragoza, 2003.

14 El final del Trienio Liberal trajo serias consecuencias para muchos liberales navarros. A Algunos, como a la familia Ligués del ex-gobernador provincial, se les marcó con un hierro candente en sus pieles una señal - en ocasiones una L - para que fueran reconocidos y estigmatizados como tales. De esta medida que hoy interpretaríamos como fascista $\mathrm{o}$ «hitleriana» no se libraron ni las mujeres ni algunos niños de las oligarquías locales constitucionalistas. Véase, Francisco José Alfaro Pérez, Historia de la villa de Cintruénigo, Cintruénigo (Navarra), 2007; especialmente en lo tocante al documento: Índice de las mujeres y hombres marcados por liberales en este pueblo. Cargos contra don Pedro Clemente Ligués, liberal exaltado, Archivo privado, ACN, Tít. ${ }^{\circ}$ II, caja 105, núm. 7.

${ }_{15}$ Recogidas nominalmente y estudiadas en sus aspectos socioprofesionales y políticos por Jesús Luís del Campo, «Pamplona tres lustros de su historia (1808-1823) (II)», op. cit., y por José Fermín Garralda Arizcun, «Antecedentes de la Guerra Carlista. Estudio sociopolítico de Pamplona en el Trienio Liberal (1820-1823)», op. cit. Igualmente interesante a este respecto es Jesús Luís del Campo, «Pamplona tres lustros de su historia (1808-1823) (I)», Revista Príncipe de Viana, núm. 162, 1981, pp. 167-244.

16 Véanse, por ejemplo, A(rchivo) G(eneral de) N(avarra), Guerra, Leg. 25, Carp. 49; o AMP, Guerra, Milicia Nacional, Leg. 2, entre otros. 
Por las investigaciones ya realizadas sabemos que entre los realistas o facciosos, como se les conocía, abundaban personas pertenecientes a lo que hoy entendemos como clase media y baja; mientras que entre los liberales o revolucionarios había mayor porcentaje de nobles e hidalgos. No obstante no se trató de una guerra de clases, pues en ambas tendencias existían personas de todo ámbito y condición. ${ }^{17}$ La estimación "oficialista» de la Pamplona del momento arrojaba unos números donde los liberales eran mayoría en una proporción de algo más de un tercio, tanto entre los civiles como entre los religiosos ${ }^{18}$ - de los que cabe reseñar la sentida tendencia realista de su obispo-.${ }^{19}$

El indulto de 28 de enero de 1822 a todos aquellos que retornaran a sus casas fue una estrategia ideada por los liberales para reconducir la situación y desmovilizar a los varones que se habían sumado a la guerrilla hasta entonces. Más de ciento cincuenta pamploneses se acogieron al mismo y regresaron a sus hogares, aunque no por mucho tiempo. Algunos días más tarde, el 11 de febrero, tratando de rebajar la creciente tensión - acentuada con la llegada a sus casas de algunos guerrilleros-, el jefe político ordenó sacar de la ciudad al regimiento de infantería de Toledo; pero para entonces Pamplona se había convertido ya en un polvorín donde la menor chispa podía hacerlo explotar, como ocurrió. La tarde del 18 de marzo un grupo de vecinos realistas y otro de militares liberales mantuvieron una acalorada discusión dando los respectivos mueras y vivas a la Constitución - iViva Dios! o ;Viva Riego!, según Martignac-20 entonando trágalas, estudiantinas y otras en plena plaza de la Constitución (del Castillo). Al día siguiente, a eso de las tres y cuarto de la tarde, en la sobremesa de unos militares bien comidos, bebidos e irregularmente

17 Vid. José Fermín Garralda Arizcun, «Antecedentes de la Guerra Carlista ...», op. cit.

${ }^{18}$ Es posible, igualmente, que se dieran algunas diferencias en el postulado político del clero navarro en función de su condición secular o regular. Véase, Francisco Miranda Rubio, «Navarra en el primer tercio del siglo XIX», Revista Príncipe de Viana, núm. 154-155, 1979, pp. 203-227.

19 Véase José Goñi Gaztambide, «Joaquín Xavier de Uriz, el obispo de la caridad», Revista Príncipe de Viana, núms. 108-109, 1967, pp. 411-414. Uriz y Lasaga fue acusado por el diario El Espectador, en su número 214, de faccioso y, aunque él escribiera el 22 de enero de 1822 negándolo, como tal participó en Bayona en la Junta de los Amigos del Orden.

20 Vicomte de Martignac, Essai historique de la Revolution d'Espagne et sur l'intervention de 1823, op. cit., T. I, pp. 388-389. 
armados se retomó la discusión del día anterior liándose a tiros. El resultado fue de 5 militares muertos, uno de ellos un capitán, y 16 heridos por los liberales; mientras que por los realistas 2 fueron los fallecidos y 13 los lastimados. La Diputación - con Álvarez de Eulate, Escudero y Munárriz a la cabeza - culpó de lo ocurrido a los de la Ciudadela tratándolos de vándalos y de tártaros. El diario El Espectador, de tintes absolutistas, no sólo era de la misma opinión, sino que afirmaba que los militares salieron armados, en contra de su código interno, buscando premeditadamente la confrontación. ${ }^{21}$

Inmediatamente se envió a Pamplona al regimiento de caballería de Lusitania y, el día 26, a otros 700 hombres dirigidos por el general López Baños procedentes del regimiento de Farnesio. Tanto el comandante general de la plaza, Mendizábal, como el jefe político de Navarra, con buen criterio, solicitaron que las tropas no entraran en la ciudad quedando acampadas en Arazuri, Erice y Sarasa. El día 30, las Cortes decretaron el desarme de los Voluntarios, imponiendo tácitamente un toque de queda en medio de una ciudad dividida, ocupada y militarizada.

De ahí al final del año se quiso mantener un status quo insostenible en el que numerosos hombres volvieron a ausentarse de sus casas para echarse al monte uniéndose a los realistas. Entre tanto, el resto del reino seguía sumido en una tónica similar donde las turbulencias lejos de menguar iban in crescendo, como daban fe los continuos incidentes armados experimentados en toda la geografía navarra (en Betelu, Buñuel, Dicasti1lo, Estella, Huarte Araquil, Los Arcos, Nagore, etc.). ${ }^{22}$ La creación de una Junta Interina pro-realista, el 10 de junio, supuso en cierta medida la reorganización institucional de los absolutistas, a través de la cual prosiguieron reclutando voluntarios a su causa.

La solución pacífica del conflicto se antojaba imposible, lo que aceleró los preparativos para una hipotética guerra abierta, tal y como se da cuenta en otra noticia anónima: Relación que da un patriota de lo que ha observado en el tiempo que ha permanecido entre los facciosos en la ciudad de Estella, desde el día 6 de octubre - de 1822- hasta el 14 de di-

21 Véase, entre otros, Florencio Idoate, «Una jornada sangrienta en Pamplona», Rincones de la Historia de Navarra, vol. 2, (1. . ed. 1966), op. cit., pp. 128-137.

22 Véase, entre otros, Anselmo de Legarda, «Navarra en el turbulento otoño de 1822», Revista Príncipe de Viana, núm. 166-167, 1982, pp. 869-893. Para el periodo comprendido desde 1821 hasta 1823 también puede consultarse José Fermín Garralda Arizcun, «La guerrilla realista en Navarra (1821-1823)», Aportes, n. ${ }^{\circ}$ 2, 1986, pp. 3-13. 
ciembre que ha salido para esta de Pamplona..$^{23}$ En ella se describe como en una casa de Larraga se hacían cartuchos, balas y cajas para la munición; como los religiosos de Abárzuza y Mañeru intensificaban sus gestiones conspirativas; de las reuniones en Estella; o de como se estaba importando pólvora de Castilla a través de Corella. No tardaría en llegar la hora en que se hiciera uso de todo ello.

\section{De las sospechas a la certidumbre: El sitio de Pamplona}

En los primeros meses del año 1823 los movimientos de los guerrilleros realistas parecían intensificarse, aunque sin demasiado éxito. A mediados de enero el cerverano (del río Alhama) Cuevillas hostigaba Tierra Estella, aunque en operaciones esporádicas y de poca relevancia. Es más, a finales de febrero, el 26, el también realista G. Bessières sufrió en Fitero una dura derrota ante los hombres del liberal lodosano Joaquín Romualdo de Pablo y Antón a «Chapalangarra». ${ }^{24}$ Sin embargo, la obstinación de los guerrilleros fue estrechando el cerco hasta darle la vuelta a la situación con anterioridad a la llegada del aliado francés. Así, por ejemplo, a finales de marzo, hacia el 26, el lumbierino Santos Ladrón puso en retirada a los hombres del citado Chapalangarra tras una sangrienta refriega en la que los constitucionalistas se vieron obligados a replegarse desde las faldas del monte San Cristóbal buscando el socaire de las murallas pamplonesas. ${ }^{25}$ Operación que los cronistas franceses enmarcan dentro de los preparativos del sitio. ${ }^{26}$ Doce días más tarde, a partir del 7 de abril, empezaron a cruzar la frontera franco-española las primeras unidades de los Cien

${ }^{23}$ Recogido en Florencio Idoate, «Las fuerzas realistas en 1822 y el servicio de espionaje», en Rincones de la Historia de Navarra, vol. 2, (1. a ed. 1966), op. cit., pp. 151-155.

${ }^{24}$ Aun hoy, en nuestros días, en Cintruénigo, localidad natal de algunos de los más destacados liberales navarros - que controlaban no sólo a su ayuntamiento sino buena parte del poder político del reino-, pero donde el pueblo llano y la oposición a las elites locales apoyaban la causa realista, siguen quemando todos los años la efigie del guerrillero liberal. Sobre la batalla de Fitero véase Ángel Ramón del Río Aldaz, Orígenes de la guerra carlista en Navarra, op. cit. y Serafín Olcoz Yanguas, Apuntes para el estudio de la historia de Fitero y del Valle del Alhama en su capítulo «La victoria de Chapalangarra en Fitero», Tudela, 2012, p. 163, entre otros.

${ }_{25}$ Para conocer más detalles sobre estas y otras operaciones consúltese, entre otros, a Ángel Ramón del Río Aldaz, Orígenes de la guerra carlista en Navarra, op. cit.

${ }^{26}$ Horace Raisson, Histoire de la guerre d'Espagne en 1823, op. cit. p. 13. 
mil hijos de San Luís en cumplimiento de los designios acordados en Verona por la Santa Alianza.

La llegada del apoyo militar francés a la cuenca de Pamplona, concretamente el 5. ${ }^{\circ}$ cuerpo del ejército de los Pirineos ${ }^{27}$ comandado por el $^{2}$ Conde de Molitor, precipitó los acontecimientos. El día $10-$ y no el 12 como recogen algunos historiadores - del mes de abril de 1823 dio comienzo el sitio de la capital del reino, como detalla el siguiente relato:

«El citado dia 10 de Abril aparecieron los Franceses en Hugarte y Villaba, y al inmediato pusieron el sitio a la Plaza dando principio a trabajar las baterias. Habiendo observado esto, el Governador de la Plaza Don Ramón Sánchez Salvador, dispuso ocupar militarmente los puestos Extramuros que son Casa Colorada, Capuchinos, San Pedro, el Molino, Santa Engracia, Casa de la viuda de García, Molino de Caparroso y puente la Magdalena, habiéndoles dado fuego a los dos primeros por la tropa de la Plaza. ${ }^{28}$

A los pocos dias de puesto el sitio quedaron demolidas las Casas y tapias de la Rochapea, pero no de un modo que no les fuera provechoso a los franceses - en zigzags,$-{ }^{29}$ como se verá más adelante». ${ }^{30}$

Molitor había dispuesto que fuera el general Conchy — que no tardaría en enfermar - la persona encargada de dirigir las operaciones de Pamplona apoyado por los cazadores de Marne y los húsares de Meuse, en coordinación con los ejércitos realistas españoles del Virrey Carlos de España. Terminado de organizar el sitio, el día 14, Molitor abandonaría Navarra dirección Zaragoza. ${ }^{31}$ No obstante, pronto surgirían las primeras disensiones entre los aliados absolutistas. Las fuentes francesas hablan que

27 El Duque de Angulema había dispuesto la división del ejército francés de España en cinco cuerpos y uno de reserva, entre los que no figuraba al mando ningún oficial que hubiera participado en la guerra de la Independencia.

28 Para conocer detalladamente y ubicar todos estos hitos urbanos citados en la documentación consúltese Juan José Martinena Ruiz, «Reseña histórica de la evolución urbana de Pamplona», Revista Príncipe de Viana, núm. 207, 1996, pp. 143-176; y, muy especialmente, Víctor Echarri Iribarren, Las murallas y la ciudadela de Pamplona, Gobierno de Navarra, Pamplona, 2000.

${ }^{29}$ Como aclara el general Abel Hugo en su Histoire de la campagne d'Espagne en 1823, op. cit., T. II, Liv. III, Cap. VIII, p. 288.

30 Anónimo, Relación de todos los acontecimientos ocurridos en el Bloqueo y sitio de la plaza de Pamplona desde el 10 de Abril de 1823 asta el 17 de Septiembre en que se rindió, Archivo privado, AFCA, signt. HCN, XIX-002.

${ }^{31}$ Horace Raisson, Histoire de la guerre d'Espagne en 1823, op. cit., p. 28. 
la insubordinación y la división de las tropas del Virrey obligaron a tener que prestarle ayuda mediante la dotación de tres oficiales franceses: M. de Barthe, Roncheroles y Recogne. ${ }^{32}$ Las españolas, en cambio, parecen apuntar a que tales desavenencias habían surgido - además de por el resquemor hacía un ejército extranjero muy mal visto- por el rumor de que el propósito del sitio era forzar una rendición pacífica, para cuyo objetivo ya se había ofrecido a los liberales no abolir la Constitución sino reformar algunos puntos de la misma. ${ }^{33}$

Consta que al principio del conflicto 30 vecinos de Pamplona fueron expulsados por su fidelidad a la causa realista, así como que entre los meses de abril y julio pudieron abandonar la ciudad unas 130 familias. ${ }^{34}$ En estos meses la situación parecía estabilizada e incluso existía cierta flexibilidad en los pases hacia uno y otro lado de las defensas. Vecinos y hasta militares sitiados se permitían transitar por el exterior de las murallas. Los sitiadores, más concretamente sus mandos y el grueso del ejército francés, confiaban todavía en una capitulación pacífica aunque, mientras ésta llegaba, sus ingenieros maquinaban la estrategia militar. Entre los sitiados, en cambio, no eran pocos los convencidos de que si el asalto no se había producido todavía era debido, sencillamente, a la imposibilidad de ejecutar aquella empresa con éxito.

«Durante los cinco meses y dias que duro el sitio, asta la rendición de la Plaza, hubo pequeñas escaramuzas en los puntos abanzados. La que fue de alguna consideración ocurrió el 16 de julio con motivo de haber salido los sitiados a segar hacia la parte del fuerte el Príncipe, que duró todo el día con mucha obstinación por ambas partes, atacando los de la Plaza contra franceses y facciosos. En este día a la hora de las seis de la tarde prendieron dos arcones de pólvora y algunas granadas que se allaban cargadas detrás de la Catedral, en donde abía montado un obus de de nueve pulgadas. En esta explosión tuvimos la desgracia de perder a Don José Bernací, Teniente Capitán de Artillería, el físico Don Bentura Crespo, Don Baltasar Sainz, unos ocho paisanos, cinco Artilleros de la tropa permanente y doce soldados de los Regimientos de infantería Príncipe y Sevilla». ${ }^{35}$

32 Geoffory de Grandmaison, L'expedition française d'Espagne, op. cit., p. 180 y sigs.

${ }^{33}$ Rafael Gambra, La primera guerra civil española (1821-1823), Madrid, 1950, p. 133.

34 Vid. José Fermín Garralda Arizcun, «Antecedentes de la Guerra Carlista ..., op . cit.

${ }_{35}$ Relación de todos los acontecimientos ocurridos en el Bloqueo y sitio de la plaza de Pamplona, ... op. cit., s.f. 
Pero conforme avanzaba el estío la paciencia de los aliados parecía estar tocando a su fin. Los preparativos para lanzar la gran ofensiva se hallaban muy avanzados e, incluso, el 8 de agosto se decidió crear un ayuntamiento realista de Pamplona, paralelo al liberal cercado, con sede en Puente la Reina. Para esas fechas la salud de Conchy era ya muy mala y un excombatiente del ejército napoleónico en la guerra de la Independencia, Jacques Alexandre de Law (Marqués de Lauriston), comenzaba a tomar las riendas desde su campamento situado en Orcoyen. Hasta el último momento se insistió en la negociación como vía para solucionar pacíficamente el conflicto, pero a las propuestas de Lauriston Sánchez Salvador contestaba, una y otra vez, que para tal fin era menester que el ejército francés saliera de suelo español y, después, la realización de un plebiscito en toda España sobre el modelo político, constitucional o faccioso, que se deseaba. La última respuesta del gobernador de la ciudadela fue dada el 26 de agosto. La muerte de Conchy, acaecida al día siguiente, fue para los absolutistas la señal de que el asunto no debía dilatarse. El tiempo de la palabra y de la espera había acabado dando paso a una actividad frenética - preludio del asalto violento a la ciudad - , ante la obstinación de los militares apalancados en ella, tal y como recoge un corresponsal de guerra para el periódico realista El Restaurador:

«Beriain, junto a Pamplona, 29 de agosto. Es continuo el paso de salchichones para la formación de baterias: la linea ha abanzado bastante según han ido llegando tropas; y todo se presenta en estado de principiar en breve el fuego.=En la plaza han tenido tres dias de mucha bulla y diversión, según cuentan las gentes que han salido auxiliadas de la oscuridad de la noche; no obstante se veian corros entre sargentos y cabos, y se notaba que muchos oficiales que tienen familia con otros se inclinaban a entregarse $=$. Un cura de la catedral, que estuvo preso, salió el viernes ultimo con pase de la plaza para llevar noticias del estado de las cosas; $y$, en efecto, volvió anteayer. Han llegado más de 200 cañones, y van llegando muchas tropas francesas». ${ }^{36}$

Obcecación liberal adereza con alardes propagandísticos y exhibiciones de fuerza destinadas a amedrentar a las tropas franco-españolas que les rodeaban: y 560 .

${ }^{36}$ Diario El Restaurador (vol. 2), n. ${ }^{\circ}$ 59, miércoles 3 de septiembre de 1823, pp. 559 
«Tres cartas contestes del mismo bloqueo de Pamplona, que tenemos a la vista, nos instruyen de los motivos que tuvieron los sitiadores para la algazara y regocijo de que se hace mérito en la carta anterior. Dudando hemos estado si los presentamos a la vista de nuestros lectores, creyendo que como nosotros se horrorizarían al oir el bárbaro furor de que se hallan poseidos unos españoles, que en este hecho manifiestan bien que pertenecen a los Cafres, o que se hallan identificados con los tigres de Hircania. Más persuadidos de que ya es bien publica a todos la fiereza de nuestros revolucionarios, nos hemos por fin decidido a presentar la última prueba en los escandalosos regocijos a que se entregaron los de Pamplona. Había llegado un parlamentario con pliegos del general Ballesteros, sin duda proponiéndoles la entrega de la plaza como estaba estipulado en la capitulación, y lejos de darse a n partido razonable, dispusieron formar una estatua que representaba al Serenísimo Señor Duque de Angulema, y habiéndola paseado en burro por las calles, la arcabucearon delante de la lápida de la Constitución, la quemaron y arrojaron sus cenizas al viento! ... Lo hemos escrito, y nuestra pluma aun se avergüenza de haber exorado en el papel una acción tan horrorosa. Los sitiados de Pamplona la han ejecutado; los mismos que antes de poco tiempo implorarán clemencia de un Príncipe generoso a quien así han escarnecido. ;Oh malvados! Sois enemigos de los tronos todos; pero vuestro odio particular a los ilustres Borbones está bien manifiesto en cuanto habeis propalado, en cuanto habeis inventado en los tres años de vuestro execrable imperio para vilipendiarlos; todos sois unos; pero estaba reservado a los sitiados de Pamplona el cometer un atentado que no tiene ejemplar ... ¿Y aun querreis invocar a favor vuestro la moderación, la concordia, la mansedumbre, la clemencia, ...? Execración y exterminio». ${ }^{37}$

Los dos primeros días de septiembre no hubo demasiados cambios, aunque se intensificó algo el cruce de proyectiles. Una operación de tanteo que no pareció preocupar en exceso a los sitiados:

«Bloqueo de Pamplona id. Ayer tarde tiraron desde la plaza bastantes granadas; pero sin efecto. Según noticias tuvieron dentro una gran fiesta en pasear por las calles y arcabucear después las estatuas de D. Santos - Santos Ladrón de Cegama, futuro Gobernador de la provincia - y D. Juanito - Juan Villanueva alias "Juanito el de la Rochapea", capitán de la División de Navarra en la guerra de la Independen-

37 Ibidem, p. 560. 
cia, coronel muy activo en ésta toma de Pamplona-. Anteayer volvió a salir el cura Urzainqui, y ayer tuvo sus sesiones con el general y la Diputación que había venido a cumplimentar al Mariscal Lauriston. Se susurra que a pesar de continuar los alborotadores cada vez más locos, se trata de entregar la plaza con ciertas condiciones. Esta mañana había reunidos más de 600 caballerías en el campo donde está el parque, y serán para dar principio a conducir los cañones a las baterías ya preparadas». ${ }^{38}$

\section{Una estrategia premeditada: La gran ofensiva}

El comienzo del fin tuvo lugar en la madrugada del día siguiente, viéndose la plaza sometida a un durísimo e incesante bombardeo que no concluiría hasta su rendición dos semanas más tarde:

«De este modo seguimos sitiados hasta que la madrugada del 3 de septiembre comenzaron los franceses ha hacer fuego de cañón a San Pedro y Santa Engracia, y en brebe se apoderaron de estos dos puntos, que los cubrían guardias de la plaza, habiendose replegado estas a aquella sin pérdida alguna, pero si la tuvieron los franceses por habersen acercado tanto que llegaron asta el puente de la Rochapea por esta parte, y por la otra a tiro de fusil. Este fue el momento en que nuestra Artillería y fusilería trabajo vigorosamente, pero no causó gran pérdida al enemigo por haberse atrincherado en todas las casas de la Rochapea, matadero, guertas, San Pedro y Santa Engracia, de donde no salio por temor del fuego que indispensablemente devia sufrir desde la muralla. A las once de la noche marcharon a sus destinos sin ser vistos, pero si fueron ofendidos dentro de las casas por la artillería de la Plaza y fenecieron muchos entre las ruinas». ${ }^{39}$

El 5 de septiembre, desde Beriain, la prensa se hacía eco del inicio de las hostilidades:

«Tres dias hace que Pamplona es un infierno: el miércoles -3 de septiembre- a las 4 de la mañana, repetidamente dieron principio a bombardear la plaza por cuatro baterias que amanecieron es-

${ }^{38}$ Diario El Restaurador, (Vol. 2), n. ${ }^{\circ}$ 63, domingo 7 de septiembre de 1823, p. 582.

39 Relación de todos los acontecimientos ocurridos en el Bloqueo y sitio de la plaza de Pamplona ..., op. cit., s.f. 
tablecidas casi tocando la ciudad, y al medio dia ya habían entrado en ellas 195 bombas haciendo mucho estrago en los edificios que se veían arder con extraordinaria humareda en todo su interior. Por la tarde todo el ejército de la línea, protegido de sus fuegos y de fusilería, tomó posición bajo tiro de cañón de la plaza, ocupando toda la Rochapea, incluso el matadero hasta la casa Colorada, fábrica del papel, la Magdalena, molino de Caparroso, y fuerte del Príncipe, habiendo hecho replegar a la bayoneta a los abanzados que los sitiados tenían en estos puntos, y cogiéndoles en San Pedro 26 peseteros o miqueletes con su comandante, y una o dos compañías de tropas. En el resto del día de más o menos siguió el fuego de la artillería para una y otra parte, siendo tal la actividad de los trabajos de los sitiadores que ayer mañana amaneció en la Rochapea una batería de $20 \mathrm{ca}$ ñones de a 24 y 36 para batir el lienzo de muralla desde el hospital hasta el mirador; y hasta 15 más de obuses, morteros y cañones se cuentan hay alrededor de a ciudad, y muy próximas a ella, siendo las más terribles las establecidas en el fuerte del Príncipe, Mendillorri, la Magdalena, etc. etc.; de modo que si hoy dan principio a operar, como dicen, si continúan obstinados, en dos días acaban con toda la ciudad y con tanto inocente como hay dentro sin haber podido salir; $y$, por otra parte, parece están decididos a asaltarla. La pluma se me cae al considerar los horrores que van a suceder si la Vírgen y San Fermín no hacen el milagro de ablandar el corazón de los tigres ya desesperados, que se meterán en el castillo abandonando la plaza y a los inocentes habitantes, que tendrán que sufrir el furor de las tropas si, como ha prometido el Mariscal Lauriston, no se las contiene con respecto a las buenas. Toda esta mañana, y hasta ahora, que son las 12, es muy poco el fuego que se hace de dentro y fuera. Ayer tarde vinieron la Diputación del Reyno y de la ciudad a quejarse al Mariscal de que todos los fuegos se dirigían a la ciudad; y les ha ofrecido dar órdenes para hacerlo al castillo». ${ }^{40}$

La celeridad con la que intervinieron la Diputación y el ayuntamiento evitaron sin duda mayor castigo y sufrimiento a la población civil. Según los padrones y recuentos municipales, desde fines del año 1819 - antes del pronunciamiento de Riego - a mediados de 1822, cuando la tensión acumulada hacía prever un desenlace violento, Pamplona había perdido cerca del $8 \%$ de su población, entorno a 1.000 de sus más de 12.500 veciy 599 .

${ }^{40}$ Diario El Restaurador, (Vol. 2), n. ${ }^{\circ}$ 65, miércoles 10 de septiembre de 1823, pp. 598 
nos. Finalizada la contienda, los huidos regresaron a sus hogares, o lo que quedaba de ellos, de tal modo que en 1824 la huella dejada por la guerra era más física, política y económica que demográfica. Del lado del ejército francés, si damos por buenos los datos publicados por A. Hugo, pudieron ser unas 370 las bajas y un número elevado de heridos a lo largo de todo el conflicto. ${ }^{41}$

Gracias a las crónicas periodísticas conocemos una evolución casi diaria de los hechos. En la de 8 de septiembre, nuevamente desde Beriain, se informaba de que:

«Los sitiadores y sitiados continúan correspondiéndose aunque con alguna lentitud: entre tanto se adelantan las obras con bastante actividad, pues según vociferan los de adentro habrá necesidad de todo. Se jactan temerarios de que harán olvidar la memoria de Sagunto; pero ellos mudarán de parecer porque son como todos sus hermanos. Hay batería que se forma a medio tiro de la ciudad; y la mayor parte de las tropas está acampada en las hondonadas más cercanas a la plaza». ${ }^{42}$

Para aquel día ya se habían puesto en funcionamiento - en las baterías preparadas para ello- unos 80 cañones dirigidos por el general Damrémont. Y, cuatro días más tarde, en esta ocasión desde Galar, el 12 de septiembre, se explicaba como:

«El fuego de la plaza y ciudadela de Pamplona continúa con bastante tesón; pero les corresponde las baterías de morteros y obuses desde las inmediaciones de Ansoain, Artica, Santa Lucía, camino para el campo santo, camino de Puente, al cuarto de legua, y la de Mendillorri: Los campamentos franceses se hallan sobre el campo santo a la caída de la altura, enteramente cubiertos de la plaza; en la llanura de la venta de Zizur hay 60 piezas de cañón para abrir brecha. El -día10 a las 8 de la noche dieron principio 30 hombres a la primera paralela que dista de la ciudadela poco más de medio tiro de fusil: da principio desde el camino de Barañain hasta el nacimiento de la fuente del León, un poco más atrás, y desde aquí sigue hasta el fuerte del Príncipe por detrás de la cruz negra que está en el crucero del camino de

${ }^{41}$ Abel Hugo, Histoire de la campagne d'Espagne en 1823, op. cit., T. II, Liv. III, Cap. VIII, p. 290.

${ }^{42}$ Diario El Restaurador, (Vol. 2), n. ${ }^{\circ}$ 67, viernes 12 de septiembre de 1823, p. 616. 
Tafalla con el que pasa por detrás de la ciudadela: en este número no entran los 1.500 hombres que hay en el fuerte del Príncipe trabajando parte de ellos una batería muy buena que, por su inmediación, sufre mucho fuego de la plaza y ciudadela. Hoy continúan trabajando y están perfectamente cubiertos en la paralela: la ciudadela hace bastante fuego de cañón y fusilería (que la estoy oyendo mientras escribo ésta), pero todo este fuego es inútil: es regular que esta noche se adelanten algunos trabajos hasta la estacada, y que mañana juegue ya la batería del Príncipe.

Por todas partes andan multitud de carros conduciendo salchichones, y se están llenando millares de sacos de tierra: en fin, en breve deben obrar ya las baterías contra la ciudadela, esto es, de cañones, que hasta hoy solo juegan morteros y obuses. El daño que se ha causado en la ciudad ha sido indispensable; pero en el día todos los fuegos veo se dirijen a la ciudadela, sin duda que las súplicas de la Diputación y ayuntamiento han hecho buen efecto como era regular. Se construyen nuevas baterías cerca del puente de Santa Engracia, y detrás del convento de San Pedro. Los franceses siguen ocupando la Arrochapea, por cuyo lado el día menos pensado caerá buena porción de muralla por las minas.

Los locos de Pamplona cada vez más chocantes, y por fin logran su gusto que es la destrucción de Pamplona, que tanto ansiaban, como usted no ignora, su fidelidad sin ejemplo al Rey. Ayer llegaron 1 carros más de palas y picos después de la multitud que había, y 13 da sacos de tierra con dos compañías de artilleros. Ayer y hoy, aunque ha hecho bastante fuego la plaza y la ciudadela, apenas se ha contestado por las baterías». ${ }^{43}$

La estrategia de los asaltantes estaba bien organizada. El tiempo de tanteo, dejado a los sitiados para que depusieran las armas y entregaran su plaza pacíficamente, había sido dedicado a la elaboración de un minucioso estudio de la fortaleza amurallada que componía en sí toda la ciudad a comienzos del siglo XIX. Concluido el mismo, las operaciones se desarrollarían en unas fases predeterminas con la intención de acorralar finalmente al enemigo dentro de la ciudadela y ahí provocar su rendición o su ruina.

El 12 de septiembre de 1823 el Conde de Guilleminot daba por finalizada la primera de ellas. Con la relación que hizo de la misma, no sólo podemos complementar la versión de nuestro anónimo liberal, sino que

${ }^{43}$ Diario El Restaurador, (Vol. 2), martes 16 de septiembre de 1823, pp. 647 y 648. 
podemos intuir ciertas «disonancia» en el informe oficial dictado interesadamente por el militar francés:

«Ejército de los Pirineos. Boletín 33. Las operaciones del sitio de Pamplona comenzaron el 3 del corriente. Era necesario para que los Ingenieros pudiesen reconocer los alrededores de la plaza y abrir las trincheras, que el enemigo fuera echado fuera de las cercanías que aun ocupaba; en consecuencia el Sr. Mariscal, Marqués de Lauriston, hizo atacar los arrabales de Rochappea y de la Magdalena, el convento de San Pedro y la casa blanca situada sobre el camino de Tolosa por la séptima división que manda el general de Famin compuesta del $3 .^{\circ}$ ligero, $6 .^{\circ}, 9{ }^{\circ}$ y $14 .^{\circ}$ de línea. Este ataque empezó a las cinco y media de la mañana, y a las siete y media los arrabales fueron ocupados por nuestras tropas, las que bajo una lluvia de metralla se han apoderado con la mayor intrepidez de las casas que estaban agujereadas y atrincheradas. Por otro lado la duodécima división mandada por el teniente general Pecheux compuesta del 20 ligero, 33 y 40 de línea, apoyado por el tercer regimiento de húsares obraba de concierto con la división Española bajo las órdenes del teniente general Conde de España al frente de la orilla izquierda del Argó - Arga-. En esta parte el Mariscal de campo Fermín con el 40 y la compañía de granaderos del Infante D. Carlos ocupó el reducto del Príncipe, y el enemigo arrojado de todos sus puestos se vio obligado a entrar en la plaza. $=$ El Señor Mariscal Marqués de Lauriston da cuenta a S.A.R., que el ataque de los dos arrabales ha sido conducido con un vigor extraordinario por el general Fermín; que el General Quinsonas ha sido quien se apoderó del arrabal de la Magdalena, y que ha sido auxiliado con la mayor ligereza por los generales Higonet y de Eressan=. A los gritos de viva el Rey se tomó la casa blanca por el $3 .^{\circ}$ de ligeros, conducido por el Coronel Conde de $S^{T}$ Gilles que fue gravemente herido - militar bretón que fallecería poco después - ${ }^{44}$ como también el jefe de batallón de $S^{\text {ta }}$ Colomba: el ataque de esta casa ha sido sostenido por el General Damremont de la 12 división, quien con un batallón del 20 ligero, hizo un movimiento de flanco muy ventajoso. Los tenientes generales Pechers y España han maniobrado igualmente con mucho valor y habilidad: los ataques de la infantería han sido seguidos con una constancia admirable, por un escuadrón del $3 .^{\circ}$ de úsares, y otro del $3 .^{\circ}$ de cazadores dispuestos para sostenerlos en el caso que el enemigo hubiese intentado una salida. La conducta de las tropas de diferentes armas es superior

${ }^{44}$ Tal y como se explica Abel Hugo, Histoire de la campagne d'Espagne en 1823, op. cit., T. II, Liv. III, Cap. VIII p. 288 y sigs. 
a todo elogio y el Sr. Mariscal Marqués de Lauriston, manifestando a S.A.R. los nombres de los que se han distinguido particularmente, le indica que ninguno de los soldados franceses han mostrado más ardor y valor que los que han tenido parte en este brillante ataque, con lo que se ha logrado perfectamente lo que se deseaba no habiendo costado más que ocho hombres muertos y 60 heridos, no obstante, las dificultades extraordinarias que ha habido que vencer. No ha podido saberse la pérdida del enemigo; por haberse verificado la acción bajo las murallas de la misma plaza. =En el cuartel General del Puerto de Santa María el 12 de setiembre de 1823=. Por orden de S.A.R. =El mayor General $=$. Conde de Guilleminot». ${ }^{45}$

A esas alturas ya no había dudas de las intenciones de unos y de otros. El cerco no sólo seguía estrechándose, sino que el armamento pesado empleado se había multiplicado exponencialmente a lo largo de las últimas jornadas. Era solo cuestión de tiempo. A la desesperada, los liberales continuaron haciendo alardes propagandísticos de una fuerza que ya no tenían, pero en su barbaridad lejos de amedrentar a los sitiadores solo lograron avivar más sus deseos de venganza:

«Bloqueo de Pamplona 13 de setiembre. Son muchísimas las bombas que han tirado los sitiadores, y se sabe que han arruinado bastantes edificios; de modo que consternados los habitantes levantan sus gritos y lamentos al cielo, de lo que se ríen y mofan los jacobinos y republicanos que abundan en aquella población. Los infantes caribes se hacen sordos a los consejos prudentes de los hombres de juicio y buenos españoles, que les suplican desistan de su empresa temeraria y capitulen. Por la parte de la ciudad que mira a los franceses han cometido la barbarie de colgar de la muralla a un prisionero francés para que lo viesen sus compañeros de armas; y, en la muralla que mira a nuestros voluntarios, han clavado a un voluntario de Navarra que tenían prisionero; es probable que lo clavarían vivo. Este doble atentado ha irritado tanto a los sitiadores, que están desesperados y deseando vivamente se les de la orden de asaltar la plaza. Se asegura que para el día 20 se pondrán 20 baterías con dirección a la ciudad y ciudadela, capaces de arruinar en pocas horas la plaza y castillos. Son inmensos los trabajos que se hacen con este fin. Los comestibles que había en los Conventos y casas de Pamplona los han arrebatado y metido en el castillo, de donde distribuyen cortísima ración a los mismos a quienes des-

45 Diario El Restaurador, (Vol. 2), n. ${ }^{\circ}$ 73, jueves 18 de septiembre de 1823. 
pojaron de sus víveres-. Aseguran que han pasado al campo de los franceses unos 100 soldados del regimiento de Jaén, y éstos dicen que están resueltos a pasarse otros 200 más (...)» ${ }^{46}$

Ciertamente la destrucción en el caserío debió ser considerable, pero los pamploneses, pertrechados en los lugares más seguros de la ciudad, debieron sufrir escasas pérdidas humanas. Además, muchos de aquellos cañonazos - siguiendo unas directrices clásicas - arrojaban animales en descomposición y bolas incendiarias en un intento por quemar y contagiar a los cercados:

«Desde este día asta el 16 del mismo no cesaron los franceses de tirar bombas y granadas en número de ocho mil y muchísimas balas rasas, tampoco cesaron de hacer caminos cubiertos, día y noche trabajando unos cinco mil hombres con tal progreso que en los 14 días de fuego continuo pusieron las baterías a tiro de carabina de la Plaza. Pero es de advertir que una de las más próximas, colocada en el camino que ba desde Santa Engracia a San Pedro, se les inutilizó por las baterías de la Plaza, que miran a esta parte, pues se tiró con mucho acierto.

Hacían fuego por 16 puntos con ciento veinte y dos piezas de cañón de grueso calibre, veinti y dos morteros y cuarenta y tantos obuses de nueve pulgadas, siendo de notar que las bombas y granadas enemigas traían mistos incendiarios y pestilentes. El estrago causado en los edificios de la Ciudad fue grande, e igualmente el de la Ciudadela, pero la pérdida de gente, tanto militar como de paisano, fue de poca consideración». ${ }^{47}$

El 14 de septiembre el ayuntamiento liberal de Pamplona era plenamente consciente de la proximidad de la derrota. Dicho día se reunió para tratar la situación de un probable asalto a la ciudad temeroso de que aquello otorgara a los asaltantes «derecho de saqueo». El acuerdo alcanzado fue que, llegado el momento, el ayuntamiento pamplonés ofrecería negociar la entrega de un dinero a cambio de evitar tropelías. Dinero que saldría no del común, sino de los liberales más pudientes de la ciudad. ${ }^{48}$

${ }^{46}$ Diario El Restaurador, (Vol. 2), n. ${ }^{\circ} 74$, viernes 19 de septiembre de 1823, pp. 675 y 676 .

47 Relación de todos los acontecimientos ocurridos en el Bloqueo y sitio de la plaza de Pamplona desde el 10 de Abril de 1823 asta el 17 de Septiembre en que se rindió. Op. cit., s.f.

48 Véase Jesús Luís del Campo, «Pamplona tres lustros de su historia (1808-1823)», op. cit. 


\section{El final de la resistencia: La capitulación de la plaza}

La penúltima fase prevista de este episodio bélico dio comienzo en la madrugada del día 16 de septiembre, si bien los acontecimientos hicieron que la última - que hubiera sido el asalto a la bayoneta tanto de la ciudad como de la ciudadela - no fuera necesario ejecutarla. A eso de las cuatro y media de la mañana se intensificaron muchísimo los bombardeos sobre la Ciudadela llegando a abrir su muralla, tal y como se publicaba en un escueto comunicado que reflejaba el progreso:

«A lo que dijimos ayer sobre Pamplona sólo hay que añadir: Que está abierta brecha en la ciudadela». ${ }^{49}$

Aquel mismo día 16 un corresponsal, desde Vitoria, hacía un balance - que no deja de ser meramente estimativo- sobre la destrucción física del casco urbano a causa del bombardeo recibido hasta esa fecha:

«Pamplona en el primer bombardeo ha padecido infinito: 66 casas, 3 conventos y parte de la catedral han sido destruidos. Continúa el segundo bombardeo, y no sabemos si se darán a la razón. Se ignora el número de personas muertas. Dos soldados que pudieron fugarse y han pasado por ésta, dicen, que han fallecido muchas personas de hambre, $y$ entre ellas algunas religiosas». ${ }^{50}$

Semidestruida, sin artillería y envuelta en disensiones internas, la Ciudadela enarbolaría bandera blanca a las dos de la tarde de aquel mismo día 16. Poco después, un grupo de liberales exaltados la retiró armándose un pequeño tumulto dentro del fortín. Finalmente, a eso de las seis de la tarde, volvería a colocarse para poner punto y final a un sitio que había durado medio año. Ya en la madrugada del día 17, don Ramón Sánchez Salvador, como comandante general de la provincia y de la plaza, recibió dentro de la fortaleza al mariscal de campo Baron de Saint-Cyr Nugués, que acudiría en representación del Marqués de Lauriston para pactar los términos de la capitulación.

«El 16 desde la 4 1⁄2 de la mañana empezaron los franceses con la mayor obstinación a dirigir sus fuegos de bala rasa a la Ciudadela, sin que por eso dejasen de tirar como los otros días de las baterías de mor-

49 Diario El Restaurador, (Vol. 2), n. ${ }^{\circ}$ 72, miércoles 17 de septiembre de 1823, p. 656.

50 Diario El Restaurador, (Vol. 2), n. ${ }^{\circ}$ 74, viernes 19 de septiembre de 1823, p. 676. 
teros y obuses que tenían en Mendillorri, Santa Lucía y demás puntos, y a poco tiempo consiguieron apagar los fuegos de los Baluartes de la Ciudadela que miran hacia la parte del camino de Estella y Tafalla. Esta obstinación y la falta de artilleros nos obligo a poner la bandera blanca a cosa de las dos de la tarde de dicho día pidiendo parlamento. Colocada esta señal de paz o suspensión, e ignorando la mayor parte de la guarnición esta providencia hubo algunos altercados y de ellos resultó que una porción de soldados la quitaron llenos de corage, pero al fin se colocó nuevamente dicha señal - a eso de las seis de la tardey se calmaron las inquietudes. Acto continuo salió el parlamento de la Plaza y en la madrugada del 17 entró en ella el Jefe francés, que se verá en la capitulación, ha acordar con el Governador de ella, su junta ausiliar y la oficialidad la Capitulación (...)». ${ }^{51}$

Esta visión desinteresada de los hechos - si bien, evidentemente, subjetiva - no coincide en absoluto con la ofrecida y divulgada por la propaganda francesa. Allí la precariedad declarada por los sitiados fabulosamente se torna en todo lo contrario, para mayor gloria de unos vencedores que, según esta versión «dediée au Roi», entre unas semanas del mes de agosto y las primeras de septiembre un grupo de franceses se había valido para tomar la inexpugnable Pamplona:

«Precedé le 3 de septembre par une brillante affaire d'infanterie; commencé le 10 par une ouverture de tranchée qui fait honneur au génie; terminé le 16 par un feu d'artillerie vivement et habilment dirigé, et qui a miné en peu d'heures les défenses de la place. Contre une garnison plus nombreuse, et qui ê̂t pu espèrer du secours, notre armée, malgré son inmmense matériel d'artillerie, n'aurait certainemment pas pu entreprendre ce siége. L'infanterie a supplée par son zéle et sa valeur à tout ce qui manquait en munitions et approvisionnements». ${ }^{52}$

De los trece puntos estipulados en dicha capitulación podrían destacarse los siguientes. El primero, evidentemente, el que estipulaba la entrega de la plaza al ejército francés acordado así tanto por la «Gloria», como para prevenir ejecuciones sumarias y venganzas. En segundo lugar,

51 Relación de todos los acontecimientos ocurridos en el Bloqueo y sitio de la plaza de Pamplona desde el 10 de Abril de 1823 asta el 17 de Septiembre en que se rindió. Op. cit., s.f.

${ }_{52}$ Abel Hugo, Histoire de la campagne d'Espagne en 1823, op. cit., T., II, Liv. III, Cap. VIII, p. 289. 
el que trataba la situación de los prisioneros acordándose que todos serían trasladados a Francia, un lugar seguro, de donde tan sólo podrían volver tras la obtención del pertinente permiso del gobierno francés, en estricto cumplimiento del Decreto de la Regencia de 26 de junio de $1823 .{ }^{53}$ Igualmente, por su puesto, se acordaba la entrega de las armas del ejército liberal salvo las espadas, caballos y equipajes para los oficiales y las mochilas de la tropa. Se autorizaba el envío de dos carros secretos, que no serían registrados, quizás para los enseres de los oficiales o para disimular un expolio. Así mismo, quedaba pactado que a la firma del documento las puertas de la ciudadela conocidas como del Socorro y de la Taconera pasarían a control de las tropas francesas.

«Capitulación de la Plaza y Ciudadela de Pamplona combenida entre los SS Don Ramón Sánchez Salvador, Brigadier de los Exercitos Nacionales, Comandante General de la Provincia y Governador de aquellas, y el Mariscal de Campo Baron Saint Cir Nugues, Gefe EM y con poder de S E el Mariscal Lauriston, Comandante en Gefe del quinto cuerpo del exercito de los Pirineos.

Artículo 1.․ La Plaza y Ciudadela de Pamplona serán entregadas al exercito francés.

Artículo 2. . La Guarnición, es decir, el Governador, el EM de la Plaza y división, los Gefes, Oficiales y soldados, incluso el resguardo militar de Caballería e Ynfantería, serán prisioneros de guerra y conducidos a Francia con escolta francesa, saldra el 18 de septiembre de 1823 por la puerta de la Tejería y se trasladará por tránsitos o jornadas a San Juan de Pié de Puerto, se les facilitará los medios de transporte para ellos y sus familias.

Artículo $3 .^{\circ}$. Las armas de la guarnición, antes de la salida, se depositarán en la Ciudadela. Los oficiales conservarán sus espadas, caballos, equipages y los soldados sus mochilas.

Artículo $4 .^{\circ}$. Los milicianos Cazadores y Boluntarios que han tomado las armas, serán conducidos igualmente a Francia como prisioneros de guerra, podrán volver a España con permiso del Gobierno francés.

Artículo 5. ${ }^{\circ}$. Los empleados de la hacienda pública, los Médicos, Cirujanos, Farmaceuticos, como los oficiales del grado correspondiente.

53 Fermín Martín de Balmaseda, Decretos y Resoluciones de la Junta Provisional y las expedidas por su Magestad desde que fue libre del tiránico poder revolucionario, comprensivo al año 1823, Imprenta Real, Madrid, 1824, t. VII, pp. 47-49. Recogido igualmente, aunque resumido, por León Carbonero y Sol, Estracto Alfabético de cuanto contienen todos los tomos de Decretos, Boix Editor, Madrid, 1841, p. 169. 
Artículo 6. ${ }^{\circ}$. Los enfermos de la guarnición serán asistidos por el exercito francés y los médicos y cirujanos españoles hasta la curación.

Artículo 7.․ Los Gefes de los cuerpos tendrán facultades de depositar los papeles de contabilidad de sus regimientos.

Artículo $8 .^{\circ}$. Dos carros cubiertos se concederán a la salida de la guarnición sin ser registrados.

Artículo 9. . Qualquier artículo que ofrezca dudas se interpretará a favor de la guvernación.

Artículo 10. ${ }^{\circ}$. El Mariscal de Francia Conde de Lauriston, General en Gefe del 5. ${ }^{\circ}$ Cuerpo del Exercito del Pirineo interpondrá su influjo con las autoridades españolas para impedir las reacciones y benganzas políticas.

Artículo 11. . Los oficiales de Artillería e Yngenieros se nombrarán de una y otra parte para reconocer el estado del armamento, arsenales y almacenes de la Plaza.

Artículo 12. . Los Comisarios de guerra se nombrarán también para formar el inbentario de las Cajas y almacenes de todo género pertenecientes al estado.

Artículo 13. ${ }^{\circ}$. Luego que la presente Capitulación este firmada, la puerta de la Ciudadela llamada del Socorro, y la de la Taconera, se ocuparán por las tropas francesas.

Pamplona, 17 de septiembre de 1823.

Ramón Sánchez Salvador. Mariscal de Campo San Cir Nugues, y a nombre del S.E.AR. el Duque de Angulema el Mariscal Conde de Lauriston.

La Guarnición de la Plaza permanecio disponiendose para la marcha todo el dia 17 y el 18 entregamos las armas en la Taconera a las tropas francesas que ya habían entrado en ella». ${ }^{54}$

Desde Madrid, el día 20, se hacía correr la noticia a toda España:

«Son las 11 de la noche y la Gaceta extraordinaria publica la rendición de Pamplona y su ciudadela, en virtud de capitulación concedida por el Excmo. Sr. Marqués de Lauriston, quedando la guarnición prisionera de guerra. También sabemos que quedó prisionera la de Santoña, conservando los oficiales sus grados, si S.A.S. la Regencia del Reyno tiene a bien acceder a la capitulación». ${ }^{55}$

${ }^{54}$ Relación de todos los acontecimientos ocurridos en el Bloqueo y sitio de la plaza de Pamplona desde el 10 de Abril de 1823 asta el 17 de Septiembre en que se rindió. Op. cit., s.f.

55 Diario El Restaurador, (Vol. 2), n. ${ }^{\circ}$ 76, domingo 21 de septiembre de 1823. 


\section{Consideratio}

Si la guerra parecía haber terminado, la paz no llegaba. El 19 de septiembre, a pesar de no resonar ya el eco de los cañones, en Pamplona y en toda Navarra se respiraba un ambiente de máxima tensión. La batalla había finalizado sin el acto final, sin el éxtasis de la venganza, sin la borrachera de sangre inculcada por los arengadores de la tropa. Fue un epílogo pactado, razonado y humanitario, en sí una victoria a medias, donde se sobrevaloraba la capacidad del ser humano para perdonar y hallar puntos de encuentro. Ese día el objeto del deseo más animal salía escoltado por dos batallones y un escuadrón rumbo a la Navarra de Ultrapuertos, se escapaba vivo ante los ojos encendidos de los batallones de realistas navarros, integrado por unos 4.500 paisanos - dirigidos por Santos Ladrón-. ${ }^{56}$ Una solución pactada, inconcebible para unas milicias que mostraron «síntomas de descontento y aun de insubordinación» ante tales hechos. ${ }^{57}$ Desencuentro previsible ya desde aquellas tensiones internas habidas en el seno del bando faccioso en los albores del asedio. El día 18 se había reunido por última vez el ayuntamiento liberal ${ }^{58}$ de Pamplona cediendo el poder al realista el citado 19 de septiembre, al tiempo que salían de la ciudad los prisioneros de guerra.

Un día más tarde, el 20, con los liberales deportados rumbo a suelo francés, el Mariscal Lauriston hizo una proclama dirigiéndose a toda Navarra con la intención de transmitir tres ideas: la primera que el orden monárquico y social había sido repuesto; la segunda, solicitando la colaboración de los navarros con la justicia para evitar venganzas intestinas y desmanes; y, la tercera, recordando que el ejército francés estaba allí como aliado - de algún modo todavía estaban muy cercanos los acontecimientos napoleónicos -.59

56 Abel Hugo, Histoire de la campagne d'Espagne en 1823, op. cit., T., II, Liv. III, Cap. VIII, p. 290.

57 Florencio Idoate, «Los bigotes de los voluntarios realistas», Rincones de la Historia de Navarra, vol. 3, (1. ${ }^{\text {a }}$ ed. 1966), pp. 339-341.

58 Para conocer con mayor detalle el comportamiento del ayuntamiento de Pamplona en este periodo, entre otros trabajos del mismo autor, véase José Fermín Garralda Arizcun, «Las elecciones municipales de Pamplona en el Trienio Constitucional (1820-1823)», Actas del V Congreso de Historia de Navarra, vol. 2. Pamplona, 2002, pp. 21-40.

59 Diario El Restaurador, (Vol. 2), n. ${ }^{\circ} 82$, sábado 26 de septiembre de 1823, p. 747. La proclama decía, literalmente: «Navarros. Toda Navarra está libre del yugo revolucionario: la capital de la Navarra, Pamplona, se ha sometido a vuestro Rey: el Pabellón de Fdo. VII 
Los movimientos de las tropas, los sitios y desastres y las malas condiciones en que había quedado el norte peninsular, en especial Santoña, San Sebastián y Pamplona, desencadenaron que, entre los días 20 el 22 de septiembre, se declarara un brote de fiebre amarilla en la localidad guipuzcoana, donde estaba siendo embarcado parte del material pesado empleado por los franceses en el sitio de Pamplona. ${ }^{60}$ En su erradicación se dispuso la quema y el hundimiento del bergantín «Donostiarra», ${ }^{61}$ fiel reflejo del modo en que había quedado la sociedad y la economía del entorno.

En suma, una guerra sin su acto final, una victoria sin celebrar, una política titubeante y radical, y una fractura social que terminaría por perpetuarse en el tiempo. Dos meses más tarde, el 18 de diciembre de 1823, el Conde de España, virrey interino del reino de Navarra, ante una paz que no retornaba insistía a la Diputación en la necesidad de una reconciliación: «(...) solo restableciendo la paz interior en vuestras familias, es como se puede consolidar la felicidad de este Reyno (...)». ${ }^{62}$ Pero las concepciones políticas ya habían sido inoculadas en un pueblo acostumbrado hasta entonces a vivir exclusivamente de los sueños morfínicos de la reli-

flota en sus muros: las autoridades legítimas están restablecidas: vuestras leyes van a tomar su vigor.

Navarros, iguale vuestra generosidad a todos los demás nobles sentimientos que os animan para con vuestro Rey y vuestra Patria: no os entregueis a venganzas particulares: todos habeis sufrido mucho; pero dejad a la justicia el cuidado de perseguir a los culpados; no los imiteis, pues no obrariais como verdaderos Españoles: confiad en las autoridades que os gobiernan; y vuestra noble conducta atraerá acia vuestro Rey a aquellos hijos que se le han desviado, aumentando asi el número de sus súbditos fieles.

Navarros, siempre hallareis ayuda y sostén en este ejército francés, vuestro aliado, que cuando marche de España sólo quiere llevar la gloria de haberla libertado del yugo revolucionario y haberle librado su Rey.

Pamplona 20 de septiembre de 1823. -El Comandante en Jefe del 5. ${ }^{\circ}$ Cuerpo del Ejército de los Pirineos-. El Mariscal de Lauriston», recogida en Abel Hugo, Histoire de la campagne d'Espagne, op. cit., T. II, Liv. III, Cap. VIII, pp. 290-291.

60 Sobre esta cuestión, así como de la situación epidemiológica de Pamplona en los años siguientes a esta guerra véase el estudio de María Molero de Boquet, «Estudio de L-F. Briant sobre la topografía física y médica de Pamplona (1825-1828), Revista Príncipe de Viana, n. ${ }^{\circ}$ 198, 1993, pp. 91-110, sobre la obra de Louis François Briant, Essai sur la topographie physique et médicale de la villa et des environs de Pampelune, capitale de la Navarre espagnole, Paris, 1829.

${ }^{61}$ Desde Alza el 22 de septiembre, en El Restaurador, n. ${ }^{\circ} 82$, el 27 de septiembre de 1823.

${ }^{62}$ Florencio Idoate, «Los bigotes de los voluntarios realistas», op. cit. 
gión católica. En la sociedad del Antiguo Régimen algo había muerto para siempre y el proceso restaurador, en contra de sus pretensiones, no había hecho sino constatarlo y acentuarlo.

Si la confrontación ideológica se había mostrado nítidamente durante los años de la guerra de la Independencia, apuntalada con el retorno de Fernando VII y sus medidas destinadas a la reposición absolutista, el enfrentamiento del año 1823 como epílogo violento del Trienio Liberal polarizó aun más unos postulados hasta hacerlos no solo incompatibles sino irreconciliables. Y lo que es peor, este proceso afectó no sólo a las elites sociales - al antiguo reyno-, como había ocurrido en otras ocasiones, sino que caló en el pueblo llano llegando a resquebrajar la paz social desde sus más hondas raíces. La herida que acababa de ensancharse generaría en el futuro una espiral de enfrentamientos, ataques políticos y militares, que no cicatrizarían en todo el siglo XIX. Aún en nuestros días, para entender y explicar ciertos postulados ideológicos debe partirse, cual genealogía, cuando menos, de estos momentos aquí traídos. ${ }^{63}$

${ }^{63}$ Sobre el origen y la trascendencia de estas relaciones puede verse, entre otros, el estudio de Jon Juaristi, «Joseph-Agustín Chaho: Las raíces antiliberales del nacionalismo vasco», en Cuadernos de Alzate, núm. 1, San Sebastián-Madrid, 1985, pp. 72-77. 